\title{
En torno a un "escudo" de Luis XII hallado en Cacabelos (León)
}

\author{
Manuel Abad Varela *
}

Este hallazgo numismático que vamos a dar a conocer creemos que guarda, por las razones que expondremos, una estrecha relación con el camino de peregrinaciones a Santiago de Compostela. Se encontró en la villa de Cacabelos (El Bierzo, León), al pie de la iglesia parroquial de Sta. María de la Plaza, mientras realizaban unas obras en el subsuelo. Esto debió ocurrir alrededor de los años sesenta, tal como nos contó don Manuel Rodríguez Jorge, su actual poseedor ${ }^{1}$.

\section{DESCRIPCIÓN}

Luis XII de Francia (1498-1515).

Anv. / Cuadrante con las armas de Francia y el Delfinado, sol en alto. Leyenda: 管 LVDOVICVS : DEI : GRATIA : FRANCORVM : REX : G (fig. 1).

* UNED. Departamento de Prehistoria e H. ${ }^{a}$ Antigua.

Agradezco a José Antonio Balboa de Paz toda su inestimable información y ayuda, de la que guardo un grato recuerdo, asi como doy las gracias a Manuel Rodriguez, padre e hijo, por todas sus atenciones y facilidades para el estudio de la pieza. 
Rev. / Cruz flordelisada.

Leyenda: 学 XP : VINCIT : XP : REGNAT : XP : IMPERAT (fig. 2).

Metal: oro

Tipo: escudo

Peso: $3,400 \mathrm{gr}$.

Fecha: 1498-1505

Conservación: Muy buena.

Observaciones.

Presenta como particularidad todas las "S" del reverso invertidas ${ }^{2}$.
Módulo: $27 \mathrm{~mm}$.

Grosor: $1 \mathrm{~mm}$.

Ejes: 12

Ceca: Romans (Delfinado)

\section{REFERENCIA BIBLIOGRÁFICA}

J. Lafaurie: Les monnaies des rois de France. Hugues Capet Louis XII, París-Basilea 1951, pág. 129, $n .{ }^{\circ} 597$.

A. Blanchet y A. Dieudonne: Manuel de numismatique française, Paris, vol. 2, pág. 309, lám. VII, 3.

R. Friedberg y J. Friedberg: Gold coins of the world, New York 1965, pág. 95, n. ${ }^{\circ} 78$.

Esta pieza coincide en su cronología con un período coyuntural en la historia europea, como muy bien nos ha descrito Pierre Vilar ${ }^{3}$. Recordemos tan sólo que es el momento de la expansión demográfica, del aumento en la producción alimenticia, del nacimiento de las economías nacionales, del desarrollo del comercio y las comunicaciones, así como del empleo y de nuevas técnicas financieras, monetarias y comerciales.

2 Esta particularidad la admite L. CIANI: Les monnaies royales françaises de Hugues Capet à Louis XVI, Paris 1926, cuando hace el catálogo de signos especiales para la moneda medieval francesa; sin embargo, en la pág. 179 , al tratar los talleres para las acuñaciones de Luis XII, no especifica esta particularidad. Por otro lado, no resulta nada extraño por la abundancia de signos especiales que se emplearon durante esta época en cada uno de los talleres.

3 P. VILAR: Oro y moneda en la historia (1450-1920), Barcelona 1969, págs. 92-100. 
En Francia, Luis XI (1461-1483), primero, y Carlos VIII (1483-1498), después, trataron de llevar la unificación territorial al mercado monetario, tan variado entonces en talleres, monedas, pesos y ensayadores. En cuanto al metal oro, será también Luis XI el que inicia la reforma acuñando en $1475 \mathrm{el}$ «écu au soleil», por tener como en la presente moneda un sol radiante encima del escudo. Tenía un peso teórico de 3,496 gramos con una ley de 963 milésimas y pasaría a constituir desde entonces la unidad en el oro. Hemos de tener en cuenta que durante la etapa que nos ocupa, finales del siglo $\mathrm{xV}$ y comienzos del siglo $\mathrm{XVI}$, el oro era el metal en torno al cual se realizaban todas las operaciones comerciales, así como lo sería la plata en la segunda mitad del siglo XVI.

Durante el reinado de Luis XII, a quien corresponde la moneda, se observan, en el sistema monetario francés, los primeros ensayos de transición entre los modelos góticos y otros de clara influencia renacentista ${ }^{4}$. No obstante, sus acuñaciones en Francia seguirán manteniendo los tipos de sus predecesores; en cambio, las que haga en Italia, por su intervención como presunto heredero de la casa de Anjou, se adaptarán a los sistemas y diseños renacentistas que Luis XII estaba percibiendo en Nápoles y Milán ${ }^{5}$. Esta influencia italiana se observará en algunas de las piezas de oro acuñadas allí, los dobles ducados, y de una forma clara en las monedas de plate, los "testones" ${ }^{6}$, que aparecen con el retrato del rey y representan sus leyendas con caracteres latinos. Estos cambios, sin embargo, no afectarán, como decíamos, a la moneda de oro que se acuña en Francia hasta que se emitan los escudos del rey Enrique II (1547-1559).

En la pieza que contemplamos podemos observar que continúa, por un lado, con las tradicionales leyendas del escudo o «denier d'or a l'écu», desde que lo instauró el rey santo, Luis IX (1226-1270) ${ }^{7}$. Por otro lado, conserva toda la tradición medieval en sus tipos de letra gótica, y ade-

4 Principalmente lo comprobamos en las acuñaciones Franco-italianas: Piamonte y Asti (1498-1513), y en el reino de las Dos Sicilias: Nápoles y Aquila (1501-1504), Ducado de Milán (1499-1513), villa de Gênes (1499-1513), ciudad de Sabone (1499-1510), tal como se observa en H. Hoffmann: Les monnaies royales de France depuis Hugues Capet jusqu'a Louis XVI, Paris 1878, págs. 87-93.

5 Para conocer algo mejor los contactos entre franceses e italianos se puede consultar el artículo de L. COgLIATI ARANo y E. ARSLAN: "Le monnayage milanais de Louis XIl et ses antécédents sous les Sforza", La monnaie miroir des rois, Paris 1978, págs. 99-138.

6 El nombre le viene de la gran cabeza que figuraba en el anverso de las monedas de plata de Galeazzo María, Duque de Milán.

7 O. GIL FarRes: Historia universal de la moneda, Madrid 1974, pág. 131. 
más se testimonia, por medio de la "S" gótica invertida, la influencia de la época, cuando los maestros de acuñación o ensayadores ponían en sus acuñaciones puntos, marcas y particularidades. Servían todos éstos para autentificar y garantizar las emisiones de los numerosos talleres y tipos de monedas igual que para saber a quién había que pedir responsabilidades ${ }^{8}$. De todas formas, en tiempos de Luis XII, a pesar de que se buscaba por medio del autoritarismo monárquico la unificación del sistema, hasta 1507 no se avanzó en la política monetaria realizada anteriormente por Luis XI y Carlos VIII.

En el Delfinado, la zona donde fue acuñada, se mantuvo un funcionamiento «semi-real», como define Dieudonné ${ }^{9}$. Había en él cuatro talleres: el de Crémieu, Grenoble, Montelimar y el reabierto de Romans ${ }^{10}$, quizás por sus necesidades económicas en Italia. Pero, salvo el de Grenoble, todos ellos dejarán de funcionar en 1507, el año de su entrada en Milán, aquella que le organizó Leonardo da Vinci, y el mismo año también de la introducción de un nuevo motivo en los escudos de oro, el puerco espín de la Casa de Orleans.

Todavia resulta bastante difícil la clasificación cronológica de las monedas de este período. No ocurrirá 10 mismo para las de Francisco 1 (1515-1547) en que gracias a los esfuerzos de Delombargy y $\mathrm{M}$. Anatole de Barthélemy, así como al inapreciable estudio documental de $M$. de Saulcy, han permitido conocer las reformas y acuñaciones efectuadas en su reinado. En la moneda que presentamos, se aprecia, aunque no con excesiva claridad, una "G» como signo o letra al final de la leyenda del anverso. Ésta correspondería a la marca diferenciadora del maestro particular o ensayador Gérar Chastaing. Si recogemos información sobre él, de toda la que nos facilita M. de Saulcy ${ }^{11}$, tenemos que es nombrado por el rey «maitre particulier» del taller de Romans desde el 7 de marzo de 1498 y que pone como señal diferenciadora una "G», puesto que el 11 de enero de 1505 recibe una Orden por la que se le pide que debe de tomar por marca diferenciadora «GC» en lugar de la «G» solamente.

8 Donde podemos encontrar todo un muestrario de ellas es en A. BLANCHET y A DIEU. SONNE: Manuel de numismatique française, Paris 1936, 4. vols.

9 A. Blanchet, y A. Dieudonné: Ob. cit., vol. 4, pág. 175-180.

${ }^{10}$ Se sabe que en octubre de 1493 el único taller que existía en el Delfinado era el de Grenoble, que habia creado Carlos VIII por un decreto de junio de 1489 y que permanecerá abierto hasta 1772 , un mes antes de morir.

11 F. DE SAULCY: Éléments de l'historie des ateliers monétaires du royaume de France depuis Philippe-Auguste jusqu'a François / inclusivemente, Paris 1877, págs. 22 y 67. 
Aquí debió de estar hasta 1507, pues aunque este taller no se cerraría hasta el 19 de junio de 1515, sin embargo no se le cita entre los talleres que funcionan el 19 de noviembre de 1507. El 11 de junio de 1510 se le nombrará «maître particulier» por diez años del taller de Grenoble, y hemos de suponer que seguiría utilizando su nuevo distintivo además de la rosa de Grenoble. De todo esto podemos deducir que la acuñación de esta moneda puede haber sido hecha en Romans entre el 7 de abril de 1498 y el 11 de enero de $1505^{12}$.

Sobre su anverso, únicamente nos falta por reseñar que este tipo no debió de ser tan abundante como el escudo con las tres flores de lis y la corona ${ }^{13}$. En cuanto a su reverso lo encuadraríamos en el cuarto grupo de la clasificación de Dieudonné ${ }^{14}$, puesto que utiliza la asimilación de los dos escudos, el de Francia y el del Delfinado. Este sistema lo establece Carlos VI en 1385 y prevalecerá durante los reinados de Luis $\mathrm{XI}$, Carlos VIII y Luis XII, como comprobamos en este caso ${ }^{15}$.

\section{SU RELACIÓN CON LA CIRCULACIÓN MONETARIA A FINALES DEL SIGLO XV Y COMIENZOS DEL SIGLO XVI}

El escudo o la corona, como se la conoce en España ${ }^{16}$, comenzó a abrirse paso, tras la reforma de 1475 , entre el florín y el ducado, moneinvertida.

12 No perdemos de vista que nos falta todavía por resolver la incógnita de la "S»

${ }_{13}$ Sólo he visto una similar, aparte de las referencias bibliográficas, en el catálogo de subasta Collection de monnaies romaines et françcaises, Hotel Drouot, Paris, febrero 1970, preparada por E. BouRgeY, número 490. Hay colecciones importantes como la del Museo de Saint-Omer. M. Amandry, M. Dhémin, J. Lafaurie y C. Morrisson: Catalogue des monnaies d'or, Arras 1983, donde no hay ninguna moneda de este tipo.

14 A. BLANCHET y A. Dieudonné: Manuel de Numismatique française; el t. IV está realizado por A. Dieudonné: Monnaies féodales françaises, Paris 1936, pág. 179.

${ }_{15}$ El Delfín Humberto II, conde de Albon, a causa de las deudas, se vio en la necesidad de ceder sus estados al rey de Francia, Felipe VI. La abdicación la hizo en 1349 a favor del heredero de éste, el hijo mayor, Carlos. A partir de aquí el hijo primogénito del rey de Francia tomaba, a su mayoria de edad, el título de Delfín, que conservaba hasta que un nuevo heredero alcanzase la mayoría.

${ }_{16}$ El nombre de corona procede de la primera emitida por Felipe VI (1328-1350), en que figuraba una corona en el anverso; luego, aunque reformó el tipo Carlos VI (13801422), siguió manteniendo sobre el escudo de las flores de lis la corona, de ahí que conservase este nombre junto al del escudo para designar a estas monedas de oro. 
das que circulaban por todo el ámbito internacional ${ }^{17}$. El monarca francés, Luis XII (1498-1515), mantuvo también este escudo, de acuerdo con su peso oficial de $3,49 \mathrm{gr}$. y su ley de 963 milésimas que perdurará hasta la gran reforma llevada a cabo por Luis XIII (1610-1643). Esta situación dejaba al escudo en posición desairada frente a la moneda castellana, el "castellano" o "medio excelente», creado el 26 de junio de 1475 con un peso superior de $4,60 \mathrm{gr}$. y una ley más rica de 980 milésimas ${ }^{18}$.

La diferencia entre unidades monetarias de oro cuando tienen distinto peso y ley, y sobre todo en lo que respecta a la moneda francesa, traía consigo toda una problemática que se irá reflejando desde antiguo en varias disposiciones de los RR.CC. En la Pragmática dada el 28 de enero de 1480 , a petición de las Cortes de Toledo para uniformar el valor de las monedas, se fija en maravedís la equivalencia de las monedas de oro que circulan por Castilla ${ }^{19}$, pero en ella se previene contra los escudos o coronas francesas cuando dice: «que no pudiendose dar tasa cierta a las 'coronas' de Francia por su diversidad, no haya obligación de tomarlas, y que los que quisieran recibirlas las tomen por lo que valgan segun la lei que tuvieren". Esto nos demuestra las dificultades de aceptación por las que pasaban las coronas o escudos franceses, al mismo tiempo que se producia un intento de regular de alguna forma el curso de la moneda extranjera para evitar la huida de la moneda de oro hispana. Tal podemos deducir también por la Memoria que el 6 de febrero de 1480 entregaron los Procuradores a los RR.CC. al principio de su reinado ${ }^{20}$. Estas protestas obligaron a los reyes a remediar el mal imponiendo por la Real Cédula de 2 de marzo de 1480 leyes muy duras que

17 Sobre los florines pueden verse los trabajos de M. RuEda SABATER: Los florines del Mueso Arqueológico Nacional de Madrid, Madrid 1984; y “El florín: un 'dólar' bajomedieval» (Homenaje al prof. don Angel Ferrari Núñez), en la España Medieval, vol. II, Madrid 1984, págs. 865-874. Sobre el ducado se puede consultar el artículo de F. MATEU Y LLOPIS: «EI 'ducado', unidad monetaria internacional oro, durante el siglo $X V, y$ su aparición en la Península Ibérica. (Notas a propósito del hallazgo de Puerto de Santa María, Cádiz)", Anuario del Cuerpo Facultativo de A. B. y Arq., vol. II, 1934, pág. 1-34.

18 Esta habia sido creada de acuerdo con la Cédula de 26 de junio de 1475, enviada por la reina Doña Isabel a la Casa de Moneda de Sevilia. CL. SAnz ARIzMEndi: Las primeras acuñaciones de los Reyes Católicos, Separata de la Rev. Archivos Bibliotecas y Museos, Madrid 1920, nos la comenta en las págs. 6-8.

19 F. MATEu y Llopis: Catálogo de los ponderales monetarios del Museo Arqueológico Nacional, Madrid 1934, pág. 65. El recoge la referencia de D. ClEmEncín: Elogio de la Reina Católica Doña Isabel, leído en la junta pública que celebró la Real Academia de la Historia el día 31 de julio de 1807, Madrid 1820, pág. 512.

20 T. DASIT: Estudio de los reales de a ocho, también llamados pesos, dólares, piastras, patacones e duros españoles, Valencia 1950-1951, vol. I, XXIV, doc. 55. 
evitasen la fuga de moneda ${ }^{21}$. Pero por lo que se ve en la petición número 83 de la Cortes de Toledo (28, mayo, 1480) no se habían corregido estos males ${ }^{22}$. No era éste, sin embargo, un problema nuevo para los RR.CC., puesto que ya se habían visto obligados el 24 de febrero de $1475^{23}$ a dictar desde Segovia una cédula contra los habitantes del arzobispado de Sevilla y obispado de Cádiz que habían sacado o sacaban fuera de sus reinos oro, plata y vellón, tanto amonedado como sin amonedar.

Tres años después dedican prácticamente una Cédula Real, la dictada en Madrid el 19 de marzo de 1483, para solucionar los conflictos que plantean los escudos franceses en mercados y contrataciones, pues gran parte de éstas «se pagan et cumplen con la moneda de coronas de Francia, que en estos Reinos al presente se usa, el prescio de las cuales está mucho desvariado de su verdadero valor' y ordenan que a partir de entonces se tome y se dé una corona real de Francia en 328 maravedís y a las de otros señoríos de Francia en 312 , frente al castellano y medio excelente que se les señalaba un valor de 485. Al final de la misma se añade que el valor de otras monedas como las doblas de la banda (365), florines de Aragón (265), ducados y cruzados (375) se den y tomen al valor que estaban entonces ${ }^{24}$. Pero el problema seguía latente y la aceptación de la monedá francesa no estaba claramente establecida, tal como podemos comprender por la insistencia de las ordenanzas reales, ya que el 24 de enero de 1486 se manda una Real Provisión y carta a las autoridades de Guipúzcoa para que las monedas de oro y plata circulen al mismo precio que en los demás del reino ${ }^{25}$. Fernando el Católico fue más expeditivo y ordenó en Zaragoza, el 6 de febrero de 1488, que se publicasen bandos en Gerona, Vich y Seo de Urgel con el fin de que no

${ }^{21}$ CL. Sanz ARIzMEnd: Ob. cit., págs. 8 y 9, nos señala que en el Tumbo de los Reyes Católicos, tomo II, 30, del Archivo Municipal de Sevilla, se contienen las disposiciones que adoptaron los Reyes Católicos en Toledo el 2 de marzo de 1480, imponiendo penas de confiscación de bienes y hasta de muerte para aquellos que sacasen del reino excelentes y castellanos. Los comerciantes deberían declarar ante el juez o alcalde en presencia de testigos a dónde se dirigían, el tiempo que iban a estar, número de acompañantes, bestias y dinero que llevaban y juramento de que no sacaban «sino la moneda para su costa tasada por el tal juez". Para la consulta del documento, ver también T. DAsı: Estudio de los reales de a ocho, Valencia 1950, vol. I, doc. 56 .

22 T. DASI: Ob. cit. Valencia 1950-1951, vol. I, XXVII-XXIX, doc. 57.

23 CL. Sanz Arizmendi: Ob. cit. págs. 4 y 5.

24 T. DASI: Ob. cit. Valencia 1950-1951, vol. I, XXIX-XXXI, doc. 58.

25 T. DASI: Op. cit. Valencia 1950-1951, vol. I, XXXI, doc. 60. Recordado por J. LLUIS Y NAvas-Brusi: Las cuestiones legales sobre la amonedación española bajo los Reyes Católicos, Madrid 1960, vol. I, pág. 101. 
se introdujesen monedas francesas por ser falsas y contaminadas o de mucha liga, y se justificaba diciendo que su padre, Juan, ya las había expulsado por la misma razón ${ }^{26}$. Comprobamos entonces las dificultades por las que pasaba la moneda francesa.

Los RR.CC., además, intentaron entonces solucionar uno de los problemas en los cambios monetarios y decidieron por eso regularizar las pesas de las monedas de oro y plata que corrían por todos sus reinos. El 12 de abril de 1488 dieron una Pragmática en Valencia. Según ésta, además de fijar las pesas para cada una de las monedas de uso corriente entonces, incluida la del escudo o corona francesa, se fijaba cuál debía ser el peso y señal del marco, estableciéndolo en ocho onzas ${ }^{27}$. Luego se ordenó, por la Pragmática de Valladolid de 13 de octubre de 1488, hacer pesas de medio gramo para aplicarlas a las monedas de oro extranjeras en circulación, que en comparación con el castellano andaban faltas de peso ${ }^{28}$. Estas disposiciones hemos de suponer que perseguian la misma finalidad de evitar la huida de la rica moneda hispana. En cuanto al escudo francés, podemos deducir que seguía teniendo dificultades en el cambio, tal como comprobamos en la Carta Real de 27 de marzo de 1490, donde se insiste que las monedas de oro y plata corran en Guipúzcoa al mismo precio que en el resto del reino, algo que se vuelve a recordar el 20 de diciembre de 1491 y a insistir, estando a las puertas de Granada, el 26 de enero de $1492^{29}$.

Con la introducción en el mercado, en 1485, de las piezas portuguesas de Juan II (1481-1495), conocidas por el «justo» y su mitad, el «espadín", de oro de sólo 22 quilates, el sistema de cambio se complicaba y la ley de Gresham, que por cierto ya había desarrollado Oresmes dos siglos antes que éste, se cumplía perfectamente haciendo el dinero malo desaparecer al bueno.

26 J. F. SALAT: Tratado de las monedas labradas en el Principado de Cataluña con instrumentos justificativos, Barcelona 1818 (reimpresión 1982), vol. II, págs. 88 y 89.

${ }_{27}$ F. MATeu y Llopis: Ob. cit., Madrid 1934, págs. 65-75.

28 «Primeramente mandamos y ordenamos que toda la moneda de oro, assi de castellanos, como de ducados y cruzados y dobias y florines y salutes y coronas y aguilas en que ouiere falta alguna que sea menos de vn grano entero, que corra y sea auida, y se de y tome por moneda de peso, y que no lleue por la tal falta cosa alguna: y si en cualquier pieça de las dichas monedas faltare vn grano, y no llegare la tal falta a dos granos enteros, que se lleue por toda la dicha falta y mengua quatro marauedis y no mas..." F. MATEU Y LloPIS: Ob. cit., Madrid 1934, pág. 78.

29 T. DAsl: Ob. cit, Valencia 1950-1951, vol. I, docs. 60, 68, 70 y 71. Recordado por J. Lluis y Navas-Brusi: Ob. cit., Madrid 1960, vol. I, pág. 101. 
Por todo este conjunto de circunstancias se dispusieron los RR.CC. reorganizar totalmente la cuestión monetaria de sus estados. Con la Pragmática de Medina del Campo, de 13 de junio de 1497, se daba un vuelco total al sistema anterior. Debido a la falta de moneda de oro, plata y vellón, se resolvió acuñar monedas de oro iguales al ducado, de su misma ley, talla y peso, es decir, de 980 milésimas y entre 3,45 y 3,50 gramos de peso, por ser las «más comunes por todos los reynos e provincias de cristianos, e mas usadas en todas las contrataciones", y en lo que respecta a la plata y vellón también serian reformadas ${ }^{30}$. Además se daba un conjunto de disposiciones que afectaron a aspectos jurídicos, penales, sociales, etc. Con esta Pragmática se unían al área de influencia mediterránea y continuaban en un camino emprendido por Valencia en 1483, cuando adoptó el ducado. Más tarde lo sigue Barcelona en 1493, Castilla lo hace ahora, en 1497, Aragón en 1506, Mallorca en 1508 y, finalmente, Navarra en 1513.

Pero, en lo que se refiere al oro, subsistiría uno de sus viejos problemas, pues el ducado resultaba una monera rica sobre todo en relación con el escudo francés, y así los reyes tienen que seguir dando órdenes con la prohibición de que se saquen fuera del país el oro o la plata (Granada, 20 de noviembre de 1500; Granada, 20 de marzo de 1501; Toro, 8 de febrero de 1505; Pragmática del 20 de junio de 1515; etc.) y tal certeza había de que estos metales seguían saliendo, que en todas las Cortes desde la de Burgos, del 8 de junio de 1515, se pedía que esto se evitase. Éste era motivo suficientemente importante para que se le dedicase uno de los Capítulos celebrados por la Junta de los Comuneros en Tordesillas el 20 de octubre de 1520, donde se hace mención expresa del tema, indicando los castigos que rigen sobre quienes incumplan las leyes, pero además piden «que se labre luego moneda nueva en estos Reinos que sea diferente en ley y valor á la que se labra en estos Reinos comarcanos, y que sea moneda apacible y baja y de ley de veintidos quilates, que en el peso y valor venga al respecto de las coronas de sol que se labran en Francia, porque de esta manera no lo sacarán del Reino ${ }^{31}$. Se vuelve a insistir sobre esta petición en las Cortes celebradas en Valladolid el 23 de julio de 1523, señalando la urgencia de que se cumpla ${ }^{32}$. Al final, Carlos $V$ no se decidirá a emprender la reforma

\footnotetext{
T. DASI: Ob. cit., Valencia 1950-1951, vol. I, doc. 76 .

T. DASI: Ob. cit., Valencia 1950-1951, vol. I, doc. 148.

T. Dasi: Ob. cit., Valencia 1950-1951, vol. I., doc. 157.
} 
hasta el 20 de abril de 1535, cuando preparaba su campaña contra Túnez.

Comprenderemos, entonces, que los escudos écu au soleil que circularon por nuestros reinos no debieron ser escasos ya que obligaron a los reyes a dictar normas concretas, pero también, como hemos visto, acarrearon numerosos problemas no sólo por el peso sino por su baja ley. Esto nos inclina a pensar que las coronas que llegaban a la península no eran aceptadas de buena gana y si se tomaban era por razones comerciales y como tal se debieron prodigar únicamente por las zonas fronterizas o portuarias. Si observamos, a manera de ejemplo, qué es lo que se importa por la zona de Vizcaya vemos que lo más frecuente son los paños que introducían para vender los ingleses y otros extranjeros, luego se iban a Francia con el oro y la plata para comprar pasteles y vinos de Burdeos y Bayona, así como los de Alava y Vizcaya se dirigían a Francia y Gascuña para comprar cerdos ${ }^{33}$. No hay duda que el gran negocio de este momento era la lana, y el Bierzo, por razones geográficas, se encontraba fuera de su órbita.

Hemos buscado otros hallazgos de Luis XII en la Península pero no tenemos constancia de que se hayan producido. Tampoco Mateu y Llopis en su serie "Hallazgos Monetarios" ${ }^{34}$ nos cita ninguno. Si nos fijamos en los tesorillos de este período, por si hubiese alguna corona o escudo francés entre sus piezas, comprobamos que no aparece ninguna en el que nos cita Beltrán como procedente de Palencia y oculto entre el 15201522 durante la guerra de los Comuneros ${ }^{35}$; sólo en uno de los hallazgos más importantes, el ocurrido en el Puerto de Santa María (Cádiz) en 1933, cuando se limpiaban los fondos de la desembocadura del río Guadalete, se encontró una corona de Carlos VII (1422-1461), acuñada en Génova $^{36}$, entre las aproximadamente cerca de un centenar de piezas reconocidas, cuya fecha final estaría entre el 1505-1533. $Y$ no es de extrañar esta falta, si tenemos en cuenta que las necesidades de Carlos $V$, un tiempo después, eran tan apremiantes en el exterior que la mayor

33 T. DASI: Ob. cit., Valencia 1950-1951, vol. I, doc. 70.

34 Esta serie la ha publicado F. MATEU Y LLOPIS: «Hallazgos monetarios», en la revista Ampurias, IV-XIII (I al VI); Numario Hispánico, I-XI (VII-XX); y Numisma, XXI-XXVII (XXI$X X V)$.

35 A. BELTRÁN: «Ensayo sobre la cronología de las monedas castellanas a nombre de Fernando e Isabel», Numisma, III, número 7, 1953, págs. 44-56.

36 F. MATEU Y LLOPIS: Ob. cit. Anuario del Cuerpo Facultativo de A. B. y Arq. vol. II, 1934, págs. 1-34. 
parte del oro que se recibía le resultaba insuficiente para pagar todas sus deudas. Incluso los 1.200.000 écu au soleil, que Francisco I se vio obligado a entregar como rescate por los Príncipes de Francia (1529-1530), al principio estuvieron depositados en el castillo de Medina, pero pronto tomaron también el camino de Génova y Alemania para sufragar la guerra contra el turco ${ }^{37}$.

Por todo lo expuesto, entendemos que resulta raro el hallazgo de un escudo de este período en la península y sobre todo por haberse encontrado fuera de los ejes comerciales más importantes del momento. Esta es la razón que nos obliga a relacionar esta pieza exclusivamente con el lugar de su hallazgo, El Bierzo.

\section{LUGAR DEL HALLAZGO}

Como ya anunciamos, se recogió de unas obras, al pie de la iglesia parroquial de Cacabelos. Esta villa se encuentra en El Bierzo, al W. de la provincia de Lećn, en la ruta del Camino de Santiago (fig. 3), al que siempre ha estado íntimamente ligada ${ }^{38}$. Su iglesia de Santa María de la Plaza gozaba de antigua tradición entre los romeros, pues conocemos de su existencia a comienzos del siglo XII cuando el arzobispo Gelmírez la reedificó en el solar de la actual, tras los sucesos de $1108{ }^{39}$. Gómez Moreno en su Catálogo Monumental nos describió lo más destacable de la misma ${ }^{40}$. La importancia que jugaba esta villa en la ruta jacobea la podemos constatar por un hecho que conocemos. Cuando el rey Alfonso IX organizó la repoblación del vecino Castro de Ventosa, solar de la antigua Bergidum, con todo tipo de privilegios, la mayoría de los vecinos de la villa de Cacabelos, dependientes del arzobispado de Santiago de Compostela, prefirieron gozar los beneficios de una repoblación tan pró-

37 R. CARANDE: Carlos V y sus banqueros, Madrid 1965-1967, vol. 3, págs. 115-121; y T. DAsi: Ob. cit., Valencia 1950-1951, vol. I, docs. 176-188.

38 Para ampliar conocimientos sobre esta villa se puede consultar la obra de A. QUINtana PRIETO: Monografía histórica del Bierzo, Madrid 1956.

39 L. VAzQuez de Parga, J. M. ${ }^{a}$ LacarRa y J. URía Ríu: Las peregrinaciones a Santiago de Compostela, Madrid 1948-1949, 2 vols., vol. II, pág. 298.

40 M. Gómez Moreno: Catálogo Monumental de España, provincia de León (19061908), Madrid 1925, págs. 394-395. 
xima, con lo que pasaron, en lo religioso, a la jurisdicción de la Diócesis de Astorga. Ante tal situación, el Arzobispo de Santiago protesta y el rey Alfonso IX despacha un privilegio en 1209 por el que además de dar la mitad de los pechos y servicios de la nueva población a la Diócesis Compostelana por el gran número de pobladores que procedian de $\mathrm{Ca}$ cabelos, promete al Arzobispo que no ha de cambiar la ruta de los romeros, sino que ésta seguirá pasando por su villa de Cacabelos ${ }^{41}$. Esta matización ratifica la importancia que se daba al paso de los peregrinos por la villa desde comienzos del siglo xIII.

\section{LOS FRANCESES Y LA RUTA JACOBEA}

El interés por ganar el jubileo compostelano en los años santos no decayó con el tiempo sino que fue en aumento rodeándose siempre de una gran carga simbólica ${ }^{42}$. Los Reyes Católicos, además de ganar personalmente el jubileo (1486), se preocuparon de proclamar que darían protección y amparo a todos aquellos peregrinos de España, Italia, Francia, Inglaterra, Alemania, Hungría, Estados danubianos, Suecia, Noruega y cualquier otra nación, que deseasen venir en romería a Santiago ${ }^{43}$. Durante estos siglos $\mathrm{XV}$ y $\mathrm{XVI}$ será cuando se alcance la mayor conmoción, de ahí el gran número de publicaciones que surgen dedicadas al «Camino de Santiago» ${ }^{44}$.

A la hora de peregrinar, los franceses serían los de mayor alto grado de motivación, por algo al Camino de Santiago se le llamaba también «el de los franceses". Incluso algunos reyes de Francia, como Carlos $V$ en 1380 o Luis XI en 1447, cuando todavía era Delfín, mantendrían con una renta la "capilla del Śalvador» o "capilla de la Magdalena», que pasó a

41 J. González: Alfonso IX, 2 vols., pág. 327.

42 Para entrar en el mundo de los símbolos que rodea al peregrino se puede consultar la obra de X. R. MARIÑO FERRO: Las romerías/peregrinaciones y sus símbolos, Vigo 1987.

${ }^{43}$ A. López FerReiro: Historia de la S. A. M. iglesia de Santiago de Compostela, Santiago 1898-1909, vol. VII, págs. 403-404, nota 3.

${ }_{44}$ La obra en verso de H. KUENING DE $V_{A C H}$ sobre El Camino de Santiago, se edito en 1495, y también es de esta época la de Arnold de HaRF. El manuscrito de Guillermo WaY corresponde a la peregrinación que hizo en $1456 \mathrm{y}$, entre otros, el itinerario en latín con instrucciones en inglés realizado por Andrés Boorde en el siglo XVI es otra muestra. 
conocerse por esta razón como la «capilla del rey de Francia». El mismo Luis $\mathrm{XI}$ donaría también dos grandes campanas para el templo. En realidad esto era un síntoma de la presencia francesa a lo largo de toda la ruta jacobea con sus casas, hospitales y monasterios. Aquí, la moneda francesa tendría mayor aceptación y formaría parte del gran foco de la peregrinación donde se jugaban altos intereses económicos, como hemos comprobado. De esta forma, adquiere justificación el hallazgo de un escudo francés en una zona mal comunicada, y por tanto, alejada del comercio marítimo y del mercado de la lana, pero, eso sí, en plena ruta del Camino de Santiago y al pie de una iglesia. 

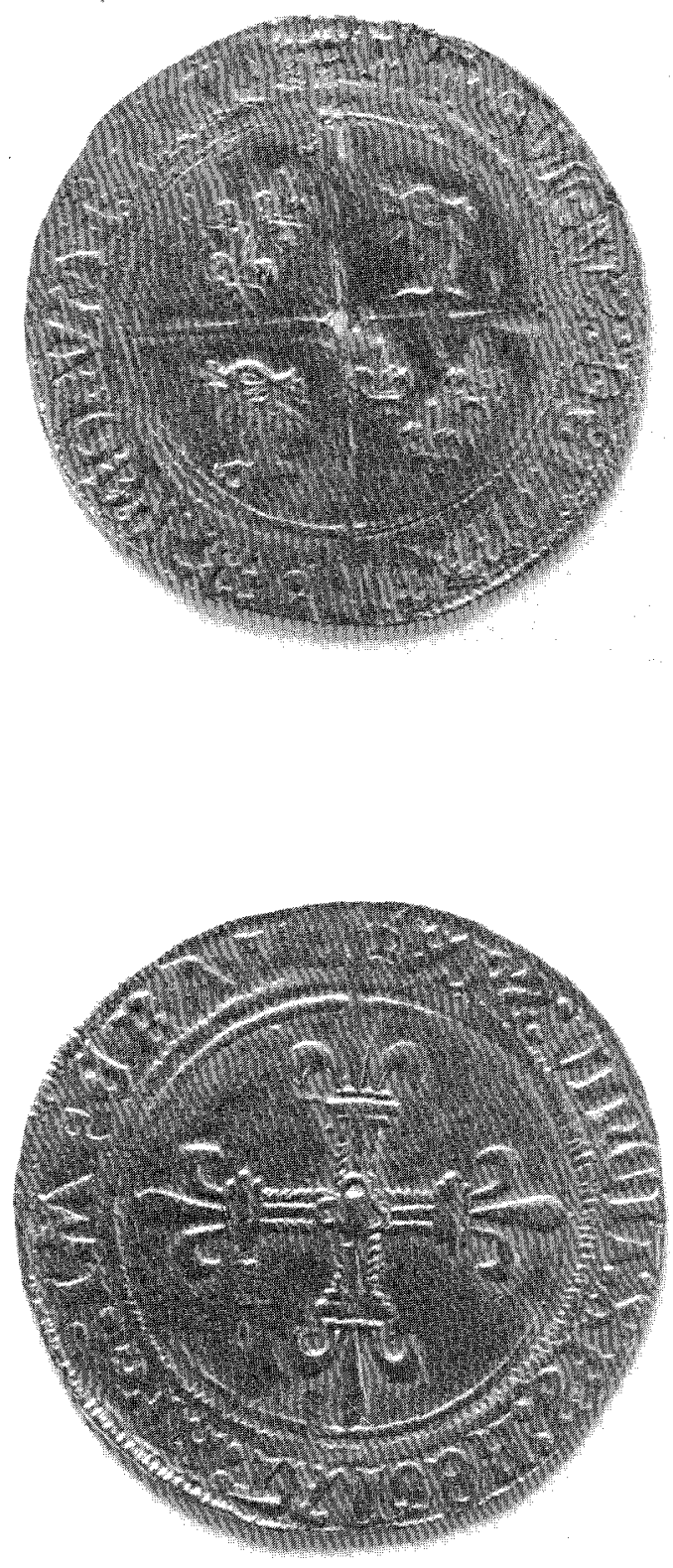
En torno a un "escudo" de Luix XII hallado en Cacabelos (León)

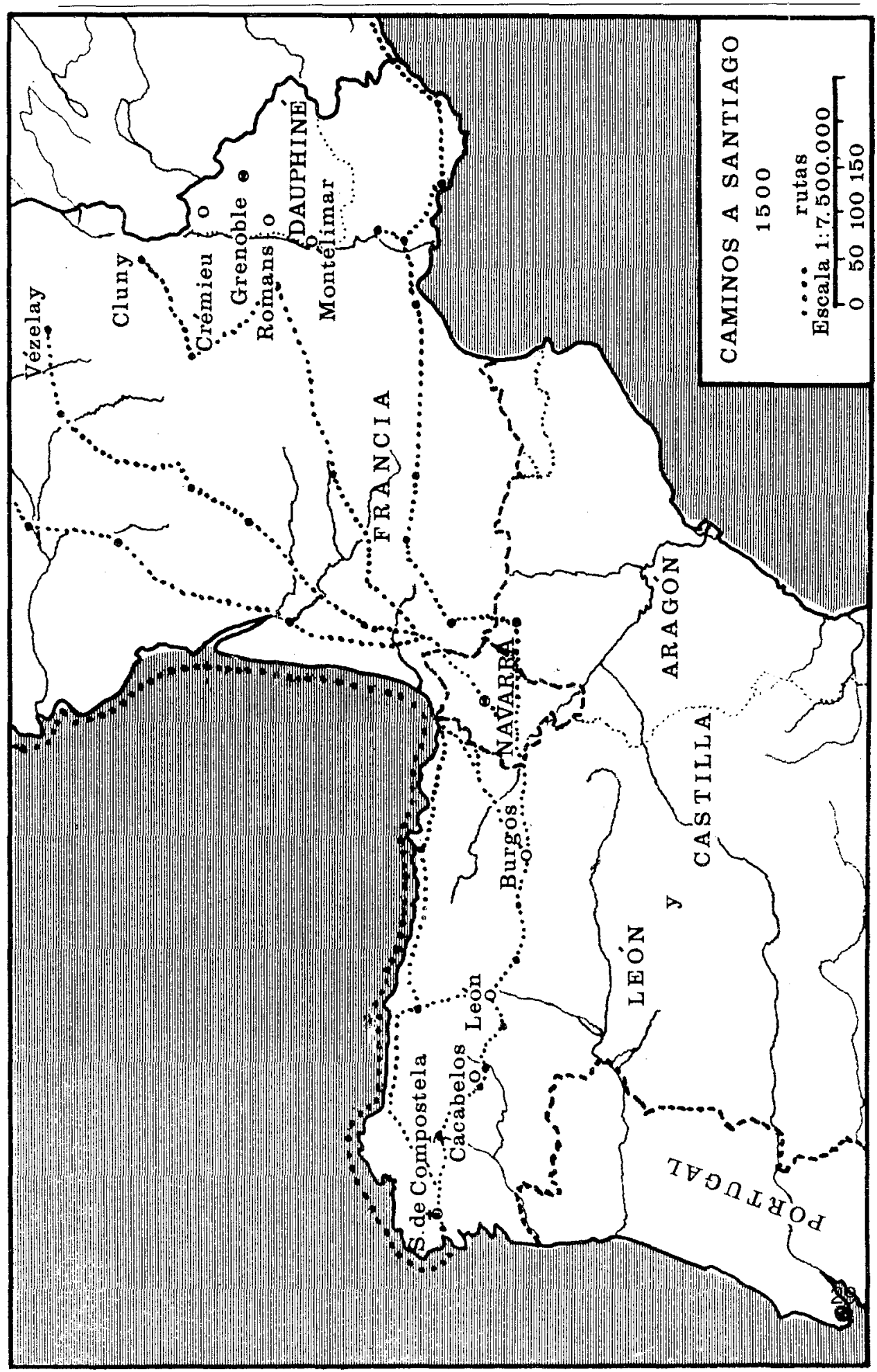




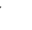

